\title{
IMPLEMENTASI METODE K-MEANS DALAM PENGKLASTERAN DAERAH PUNGUTAN LIAR DI KABUPATEN SUKABUMI (STUDI KASUS : DINAS KEPENDUDUKAN DAN PENCATATAN SIPIL)
}

\author{
Falentino Sembiring ${ }^{1}$, Octaviana ${ }^{2}$, Sudin Saepudin ${ }^{3}$ \\ 1,2,3 Universitas Nusa Putra \\ ${ }^{1}$ Falentino.sembiring@nusaputra.ac.id \\ 20ctaviana366@gmail.com \\ ${ }^{3}$ Sudin@nusaputra.ac.id
}

\begin{abstract}
Abstrak - Pungutan liar (pungli) merupakan tindakan kejahatan yang dilakukan oleh pihak yang tidak bertanggung jawab atau seseorang atau pegawai negeri atau pejabat negara dengan cara meminta pembayaran uang yang tidak termasuk kedalam aturan administrasi yang dibutuhkan. Metode K-Means dapat membantu mengklasifikasikan daerah pungutan liar di kabupaten Sukabumi pada dinas kependudukan dan pencatatan sipil. Variabel yang digunakan dalam penelitian ini E-KTP, AKTA dan Kartu Keluarga Setiap variabel memiliki nilai bobot yang berbeda. Data yang akan digunakan dalam penelitian ini adalah data laporan pada bulan Januari 2019 berbentuk SQL. Penelitian ini hanya akan membahas tentang berapa banyak kejadian pungli yang terjadi di setiap kecamatan yang ada di kabupaten Sukabumi tentang kependudukan dan pencatatan sipil. Adapun tujuan dari penelitian ini adalah untuk menentukan cluster tingkat pungutan liar tinggi, sedang dan rendah. Hasil dari penelitian ini memperoleh data indeks kecamatan dengan tingkat jumlah laporan masyarakat daerah terhadap pungutan liar, data dengan klasifikasi tingkat tinggi yaitu Cireunghas, Gegerbitung, Kalapa Nunggal, Kalibunder, Purabaya, Simpenan, Parung Kuda, Sukaraja, Nagrak, Nyalindung, Pelabuhanratu, Surade, Warungkiara. Data tingkat pungutan liar sedang terdapat pada 19 kecamatan dan 15 tingkat pungutan liar rendah. Hal ini dapat menjadi masukan kepada dinas kependudukan dan pencatatan sipil, kecamatan yang menjadi tindakan pungutan liar paling tinggi diprioritas untuk melakukan penyuluhan kepada kecamatan tersebut.
\end{abstract}

Kata kunci : Pungutan Liar, K-Means, Data Mining, Clustering

\begin{abstract}
Illegal Levies is a criminal offensse done by someone or civil servant and the government by demanding a specific amount of money outside the right protocols or policy that does not related with the official administration fees. K-Means method will be able to help for classifying the illegal levies area in sukabumi district at The Department of Population and Civil Registration. Variables that used in this research are electronic ID card, birth certificate and family card. Meanwhile, data that will be used in this research are report data on January 2016. The purpose of this research is to determine the rate of illegal levies. The result that have been collected based on the high extortion rate from each sub-districts are Cireunghas, Gegerbitung, Kalapa Nunggal, Kalibunder, Purabaya, Simpenan, Parung Kuda, Sukaraja, Nagrak, Nyalindung, Pelabuhanratu, Surade, Warungkiara, 19 sub-districts with medium rate of illegal levies and 15 sub-district with low rate of illegal levies. This can become a recommendation for The Department of Population and Civil Registration, sub-districts with the highest rate of illegal levies will be prioritized in counseling for the certrain sub-districts.
\end{abstract}

Keywords : Illegal levies , K-Means, Data Mining, Clustering

\section{PENDAHULUAN}

Indonesia memiliki jumlah penduduk terpadat ke 4 di dunia dengan jumlah penduduk 260.580 .739 juta jiwa. Indonesia menduduki posisi ke 4 setelah urutan pertama diduduki oleh negara Tiongkok. Menurut UU RI tentang Administrasi Kependudukan Nomor 23 Tahun 2006 menyatakan setiap warga Indonesia hanya diperbolehkan 1 Kartu Tanda Penduduk pada Nomor Induk Kependudukan (NIK) NIK merupakan identitas tunggal setiap penduduk dan berlaku seumur hidup untuk warga negara Indonesia dan untuk warga asing disesuaikan dengan masa berlaku izin tinggal tetap (Seberapa Pentingkah NIK, Data Kependudukan dan KTP Elektronik?, n.d.)
Salah satu permasalahan yang muncul adalah di kabupaten Sukabumi masih terjadi pungutan liar pada administrasi kependudukan. Di setiap kecamatan terdapat banyak calo sebagai perantara untuk mengurus administrasi kependudukan dengan harga sesuai tarif dan kesepakatan.

Menurut Ombudsman (2017) bentuk pungutan liar yang paling banyak terjadi di calo pengurusan sebesar $52,17 \%$, Calo antrean $19,57 \%$, permintaan biaya pembuatan $15,22 \%$, dan $2,17 \%$ kotak sumbangan seikhlasnya. (Calo dan Pungli Masih Marak, Ombudsman RI: Masyarakat Tak Mau Repot dan Pilih Jalan Pintas - Ombudsman RI, n.d.) Dengan permasalahan tersebut peneliti ingin mengelompokkan daerah pungutan liar di kabupaten 
Sukabumi dengan menggunakan metode K-Means sebagai perhitungan penentuan 3 klaster yaitu tingkat tinggi, sedang, dan rendah.

Pada tahun (2016) Kumala dkk melakukan penelitian tentang "Perbandingan K-Means Dan Fuzzy C-Means Clustering Pada Metode Radian Basis Function Neural Network (RBFNN) Untuk Klasifikasi Stadium Kanker Payudara”. Hasil dari penelitian tersebut mereka menyimpulkan bahwa metode K-Means clustering menggunakan 3 parameter data untuk menentukan tingkat nilai sensitivitas $75 \%$, spesifisitas 93,75\%, dan akurasi $80,21 \%$. (Kumala \& Wutsqa, 2016)

Dengan adanya penelitian ini, penulis berharap permasalahan tentang pungutan liar bisa dapat dinas kependudukan dan pencatatan sipil evaluasi kembali dengan mengadakan program kerja penyuluhan pada tiap kecamatan yang masuk ke dalam klaster daerah pungutan liar tinggi.

\section{A. Identifikasi Masalah}

Peneliti melihat bahwa pungutan liar di kabupaten Sukabumi masih sering terjadi dan hal tersebut membuat warga masyarakat merasa dirugikan secara finansial karena adanya pembayaran yang tidak dimintai oleh pihak terkait dan tidak tercantum dalam prosedur.

\section{B. Rumusan Masalah}

Dalam penelitian masalah yang dirumuskan adalah bagaimana menerapkan metode K-Means untuk mengklaster daerah pungutan liar di kabupaten Sukabumi.

\section{Batasan Masalah}

Penelitian ini berfokus bagaimana tingkatan (tingkat tinggi, sedang, dan rendah) terhadap pungutan liar di kabupaten Sukabumi pada kependudukan dan pencatatan sipil.

\section{Tujuan}

Untuk membangun sistem pengelompokan daerah pungutan liar ke dalam tiga klaster di kabupaten Sukabumi pada bidang kependudukan dan pencatatan sipil.

\section{E. Manfaat}

Semua Sebagai bahan evaluasi untuk melakukan program kerja yang telah dijalankan oleh pihak dinas kependudukan dan pencatatan sipil dan memberikan kemudahan untuk mengetahui daerah yang masih terjadinya pungutan liar di kabupaten Sukabumi.

\section{TINJAUAN PUSTAKA}

\section{A. Penelitian Terkait}

Agus Perdana Windarto (2017) melakukan penelitian pengeksporan buah yang berstudi kasus di Direktorat Jenderal Bea dan Cukai dengan judul "Penerapan Data Mining Menggunakan K-Means Clustering" dari penelitian tersebut agus menyimpulkan bahwa tingkat cluster tinggi yakni dua negara, dua negara cluster sedang dan enam negara cluster tingkat rendah (Windarto, 2017)

Tabel 1. Nilai Bobot Setiap Variabel

\begin{tabular}{|c|c|}
\hline Tinggi & $\begin{array}{ll}\text { 1. India } \\
\text { 2. }\end{array}$ \\
\hline Sedang & $\begin{array}{ll}\text { 1. } & \text { Singapura } \\
\text { 2. } & \text { Bangladesh }\end{array}$ \\
\hline Rendah & $\begin{array}{ll}\text { 1. } & \text { hongkong } \\
\text { 2. } & \text { Tiongkok } \\
\text { 3. } & \text { Iran } \\
\text { 4. } & \text { Malaysia } \\
\text { 5. } & \text { Nepal } \\
\text { 6. } & \text { Vietnam }\end{array}$ \\
\hline
\end{tabular}

Arsya Yoga Pratama, Iman Ardhi Prabowo, dan Alifah Normassari melakukan penelitian tentang permasalahan sering terjadi pungutan liar di Kabupaten Kudus. Penelitian tersebut diteliti pada tahun 2017 tanpa menggunakan metode clustering kmeans. Mereka melakukan pembuatan sistem berbasis android untuk melaporkan kejadian pungutan liar. Kesimpulan yang penulis dapat pada aplikasi yang mereka buat terdapat kelebihan yaitu masyarakat nantinya dapat memberikan bukti kegiatan pungutan liar berupa audio, gambar ataupun video serta keakurasian tempat terjadinya pungutan liar (Pratama et al., 2017)

\section{B. Data Mining}

Data mining adalah proses pencarian pola yang penting dari data yang ada didalam database yang besar (Rante Rerung, 2018)

Data mining merupakan istilah pattern recognition merupakan algoritma untuk pengolahan data guna menemukan pola data menjadi pengetahuan baru . Data yang diolah dengan teknik data mining akan menghasilkan suatu pengetahuan bersumber dari data lama, hasilnya untuk menentukan keputusan bisnis. (Sembiring \& Sari, 2019)

Data mining dibagi menjadi 2 kategori utama, yaitu:

1. Descriptive mining, tahapan untuk menemukan karakteristik penting dari data dalam satu basis data.

2. Predictive, tahapan untuk mempelajari bagaimana pattern design dari data set yang berupa variabel.

Teknik pengolahan data dengan bantuan algoritma data mining. pengolahan dilakukan dengan membangun sebuah pattern design, kemudian model tersebut membentuk pola data yang lain yang tidak berada dalam basis data . Tujuannya untuk memperolah pattern design untuk menjadikan data sebagai grafik untuk menjadi pengetahuan. (Gustian et al., 2018) 


\section{Metode K-Means}

$K$-means merupakan metode pengklasteran secara partitioning yang memisahkan data ke dalam kelompok yang berbeda. Dengan partitioning secara iteratif, K-Means mampu meminimalkan rata-rata jarak setiap data ke klasternya Dalam algoritma KMeans, setiap data harus termasuk ke cluster tertentu pada suatu tahapan proses, pada tahapan proses berikutnya dapat berpindah ke cluster yang lain

K-Means merupakan algoritma yang termasuk ke dalam data mining bidang Clustering atau pengklasteran data. K-Means Clustering adalah suatu metode penganalisaan data yang melakukan proses pemodelan tanpa supervisi dan merupakan metode yang termasuk mengelompokkan data secara sistem partisi.

K-Means Clustering adalah algoritma yang termasuk dalam klasifikasi terhadap objek berdasarkan atribut. Pemartisian ini digunakan untuk mencari nilai jarak minimum antara data dan nilai centroid yang telah di set baik secara random dengan cara menentukan nilai centroid berdasarkan $\mathrm{K}$ yang berupa object yang berurutan. Centroid merupakan hasil rata-rata dari sebuah bentuk objek dari seluruh titik dalam objek.

\section{Tahapan metode K-Means}

Di dalam metode K-Means memiliki beberapa tahapan yang harus dilakukan saat melakukan perhitungan untuk mencari data cluster hingga iterasi menjadi sama dengan hitungan yang sebelumnya, berikut adalah tahapan $K$-Means :

a. Menentukan k sebagai jumlah cluster (C1, C2 dan C3) yang ingin dibentuk.

b. Tentukan nilai untuk pusat cluster (centroid).

c. Hitung jarak setiap data input terhadap masing-masing centroid menggunakan rumus Euclidean Distance hingga ditemukan jarak yang paling dekat dari setiap data dengan centroid. Dibawah ini adalah persamaan Euclidean Distance :

$$
d\left(x|\quad| j, y_{j}\right)=\sqrt{\sum_{i=1}^{n}\left(x_{j}-y_{j}\right)^{2}}
$$

\section{Keterangan :}

$\mathrm{d}(\mathrm{x}, \mathrm{y})$ : jarak antara data pada posisi titik $\mathrm{x}$ dan $\mathrm{y}$

$\mathrm{x}$ :Posisi titik data pertama (pusat klaster)

y :posisi titik data kedua (data dari $\mathrm{N}$ )

$\mathrm{n}$ : jumlah atribut data

Jarak terpendek antara centroid dengan object menentukan titik klaster antar object. Adapun rumus iterasi lainnya didefinisikan sebagai berikut :

$$
v_{i j}=\frac{1}{N_{k}} \sum_{i=1}^{N_{k}} X_{i j}
$$

Rumus Penentuan Centroid Baru

Keterangan :

$v_{i j}=$ Centroid, cluster pertama pada variabel ke-j

$N_{k}=$ Jumlah data yang menjadi anggota cluster ke-i

$\mathrm{i}, \mathrm{k}=$ Indeks dari cluster

$\mathrm{j} \quad=$ Indeks dari variabel

$X_{i j}=$ Nilai data ke-k yang ada di dalam cluster ini untuk variable ke-j

d. Kemudian lakukan iterasi selama partisi data masih bergerak (tidak ada lagi objek yang bergerak ke partisi lain), bila masih maka ke poin 3 .

e. Bila grup data sekarang sama dengan grup data sebelumnya, maka hentikan iterasi. Data telah dipartisi sesuai nilai centroid akhir.

\section{E. Kerangka Berpikir}

Adapun kerangka berpikir dalam penelitian ini adalah sebagai berikut ini :

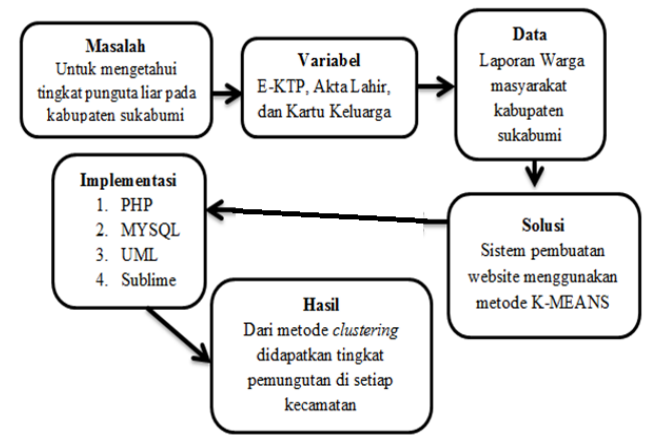

Gambar 1. Kerangka berpikir

\section{METODE PENELITIAN}

\section{A. Tahap Pengolahan Data}

Pengolahan data dilakukan untuk mengetahui hasil dari data yang diteliti. Data yang telah ada diproses menggunakan metode K-Means untuk mengklaster data pemungutan liar pada setiap kecamatan dan Kabupaten di Sukabumi.

Sebelum ke tahap perhitungan K-Means data SQL akan dipilih untuk dilakukan filtering, setelah data cleaning maka dilakukan pemasukan data nilai bobot untuk proses perhitungan ke tahap selanjutnya. Di bawah ini tabel nilai bobot yang diberikan pihak dinas kependudukan untuk setiap kriteria: 
Tabel 2. Nilai Bobot Setiap Variabel

\begin{tabular}{|l|c|}
\hline \multicolumn{1}{|c|}{ Variabel } & Nilai Bobot \\
\hline Kartu Keluarga & 3 \\
\hline Akta & 2 \\
\hline E-KTP & 1 \\
\hline
\end{tabular}

\section{B. Tahapan Clustering}

Dalam menentukan cluster dibutuhkan sebuah flowchart untuk menentukan alur perhitungan. untuk lebih jelasnya dapat dilihat flowchart berikut ini

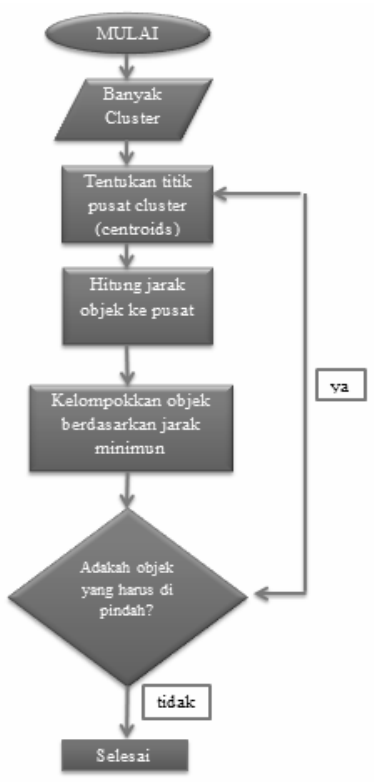

Gambar 2. Flowchart Tahapan pengelompokan data

\section{Tahapan Analisis data}

Penulis melakukan analisis pada data pemungutan liar di Kabupaten Sukabumi untuk upaya pengelompokan atau mengklaster data pemungutan liar di setiap kecamatan kabupaten Sukabumi. Data yang sudah diperoleh dari data laporan warga yang berbentuk data SQL dihitung dengan nilai bobot selanjutnya diolah menggunakan perhitungan KMeans (Ghosh \& Kumar, 2013) Melakukan clustering, data yang didapat akan dihitung terlebih dahulu berdasarkan banyaknya kecamatan untuk upaya melihat pemungutan liar yang paling banyak dilakukan. Kriteria yang digunakan yaitu sebanyak 3 kriteria penilaian yaitu Kartu keluarga(3), Akta (2) dan E-KTP(1) dapat dilihat pada tabel 2 data pemungutan liar.

Tabel 3. Data Pungutan Liar

\begin{tabular}{|c|c|c|c|c|} 
No & Kecamatan & E-KTP & Akta Kelahiran & $\begin{array}{c}\text { Kartu } \\
\text { Keluarga }\end{array}$ \\
\hline 1 & Bojong Genteng & 1 & 5 & 4 \\
\hline 2 & Cidolog & 1 & 1 & 3 \\
\hline 3 & Cireunghas & 5 & 2 & 6 \\
\hline 4 & Kebonpedes & 2 & 1 & 1 \\
\hline 5 & Lengkong & 3 & 4 & $\ldots .$. \\
\hline$\cdots$ & $\ldots \ldots \ldots$ & $\ldots \ldots$ & $\ldots \ldots$ & 5 \\
\hline 47 & Cisolok & 2 & 6 & \\
\hline
\end{tabular}

\section{Centroid Data}

Centroid merupakan titik pusat data untuk menghitung rata-rata vector sebagai centroid. Dalam penerapan algoritma K-means dihasilkan nilai titik tengah atau centroid dari data yang didapat dengan ketentuan bahwa klasterisasi yang diinginkan adalah 3 , Penentuan cluster dibagi menjadi 3 bagian yaitu cluster tingkat pemungutan liar tinggi $(\mathrm{C} 1)$, tingkat pemungutan liar sedang $(\mathrm{C} 2)$, dan tingkat pemungutan liar rendah (C3). Penentuan titik cluster (C1) diambil dari data nilai maksimal, untuk cluster (C2) nilai data rata-rata, dan cluster (C3) diambil dari nilai data minimal atau nilai terendah. Sehingga posisi centroid juga terdapat 3 titik. Penentuan nilai titik cluster tersebut dapat dilihat Tabel 3 dibawah ini:

\begin{tabular}{|r|r|r|r|}
\hline & T & B & C \\
\hline C1 & 7 & 18 & 24 \\
\hline C2 & 3 & 7,468085106 & 10,53191489 \\
\hline C3 & 1 & 2 & 3 \\
\hline
\end{tabular}

Keterangan :

$$
\begin{aligned}
& \mathrm{A}=\text { E-KTP } \\
& \mathrm{B}=\text { Akta Kelahiran } \\
& \mathrm{C}=\text { Kartu Keluarga }
\end{aligned}
$$

\section{E. Perhitungan Metode K-Means}

Setelah data sudah ada maka dimasukkan kedalam rumus untuk tahap pengklasteran data, dan dibawah ini adalah contoh perhitungan dari data yang ada setelah dimasukkan ke dalam rumus K-Means:

$$
d\left(x|\quad| j, y_{j}\right)=\sqrt{\sum_{i=\mathbf{1}}^{n}\left(x_{j}-y_{j}\right)^{2}}
$$

Sehingga menentukan data cluster

$$
\begin{aligned}
& d\left(x_{1}, c_{1}\right)=\sqrt{\left(a_{1}-c_{1 a}\right)^{2}+\left(b_{1}-c_{1 b}\right)^{2}} \\
& d\left(x_{2}, c_{1}\right)=\sqrt{\left(a_{2}-c_{1 a}\right)^{2}+\left(b_{2}-c_{1 b}\right)^{2}} \\
& d\left(x_{2}, c_{1}\right)=\sqrt{\left(a_{3}-c_{1 a}\right)^{2}+\left(b_{3}-c_{1 b}\right)^{2}} \\
& d\left(x_{4}, c_{1}\right)=\sqrt{\left(a_{4}-c_{1 a}\right)^{2}+\left(b_{4}-c_{1 b}\right)^{2}}
\end{aligned}
$$

Sehingga

$$
\begin{aligned}
& C 1=\sqrt{36+64+144} \\
& C 1=\sqrt{244} \\
& C 1=15,62049935
\end{aligned}
$$

Dari hasil perhitungan diatas didapatkan hasil bahwa jarak data pertama dengan pusat cluster pertama adalah 15,62049935.Pada tahapan selanjutnya menentukan C2 menggunakan rumus seperti berikut ini 


$$
\begin{aligned}
& d\left(x_{1}, c_{2}\right)=\sqrt{\left(a_{1}-c_{2 a}\right)^{2}+\left(b_{1}-c_{2 b}\right)^{2}} \\
& d\left(x_{2}, c_{2}\right)=\sqrt{\left(a_{2}-c_{2 a}\right)^{2}+\left(b_{2}-c_{2 b}\right)^{2}} \\
& d\left(x_{2}, c_{2}\right)=\sqrt{\left(a_{3}-c_{2 a}\right)^{2}+\left(b_{3}-c_{2 b}\right)^{2}} \\
& d\left(x_{4}, c_{2}\right)=\sqrt{\left(a_{4}-c_{2 a}\right)^{2}+\left(b_{4}-c_{2 b}\right)^{2}}
\end{aligned}
$$

Sehingga

$$
\begin{aligned}
\mathrm{C}_{2} & =\sqrt{4+6,41059303045903+2,15527389020371} \\
& =\sqrt{12,5658669206627} \\
& =3,544836655
\end{aligned}
$$

Dari hasil perhitungan diatas di dapatkan hasil bahwa jarak data pertama dengan pusat cluster kedua adalah 3,544836655.

\begin{tabular}{|c|c|c|c|c|c|}
\hline \multirow{2}{*}{ No } & \multirow{2}{*}{ Kecamatan } & \multicolumn{3}{|c|}{ Jarak Ke Centroid } & \multirow{2}{*}{ Terdekat } \\
\hline & & $\mathrm{Cl}$ & $\mathrm{C} 2$ & $\mathrm{C} 3$ & \\
\hline 1 & $\begin{array}{l}\text { Bojong } \\
\text { Genteng }\end{array}$ & 15,62049935 & 3,544836655 & 12,04159458 & 3,544836655 \\
\hline 2 & Cidolog & 22,737634 & 6,020524726 & 6 & 6 \\
\hline 3 & Cireunghas & 15,3622915 & 8,473482723 & 15,65247584 & 8,473482723 \\
\hline 4 & Kebonpedes & 24,59674775 & 7,172043456 & 3,16227766 & 3,16227766 \\
\hline 5 & Lengkong & 23,60084744 & 7,550673839 & 6,32455532 & 6,32455532 \\
\hline & ……….......... & & & & \\
\hline 47 & Cisolok & 11,91637529 & 6,442207473 & 15,65247584 & 6,442207473 \\
\hline
\end{tabular}

$$
\begin{aligned}
C_{3} & =\sqrt{0+64+81} \\
& =\sqrt{145} \\
& =12,04159458
\end{aligned}
$$

Dari hasil perhitungan diatas didapatkan hasil bahwa jarak data mahasiswa pertama dengan pusat cluster ketiga adalah 12,04159458. Setelah keseluruhan data dihitung maka didapatkan hasil jarak berikut untuk Iterasi 1:

Gambar 3. hasil perhitungan literasi pertama

Dari data pemungutan liar yang sudah ada

\begin{tabular}{|c|c|c|c|c|}
\hline \multirow{2}{*}{ No } & \multirow{2}{*}{ Kecamatan } & \multicolumn{3}{|c|}{ Jarak Ke Centroid } \\
\hline & & C1 & $\mathrm{C} 2$ & $\mathrm{C} 3$ \\
\hline 1 & Bojong Genteng & & $\mathrm{x}$ & \\
\hline 2 & Cidolog & & & $\mathrm{x}$ \\
\hline 3 & Cireunghas & & $\mathrm{x}$ & \\
\hline 4 & Kebonpedes & & & $\mathrm{x}$ \\
\hline 5 & Lengkong & & & $\mathrm{x}$ \\
\hline$\ldots .$. & ……………...... & $\ldots \ldots \ldots \ldots \ldots$ & $\ldots \ldots \ldots \ldots$ & $\ldots \ldots \ldots \ldots$ \\
\hline 47 & Cisolok & & $\mathrm{x}$ & \\
\hline
\end{tabular}
didapatkan pengelompokan pada iterasi 1 untuk 3 cluster tersebut. Cluster tingkat pemungutan liar tinggi (C1) yaitu Prabaya, cluster tingkat pemungutan liar sedang (C2) yaitu ada 35 kecamatan dan cluster tingkat pemungutan liar rendah (C3) yaitu ada 43 kecamatan lainnya dan cluster tingkat pemungutan liar rendah.

Proses pengelompokan data pada iterasi 1 dan Clustering digambarkan pada gambar berikut:

Gambar 4. Clustering pengelompokan data

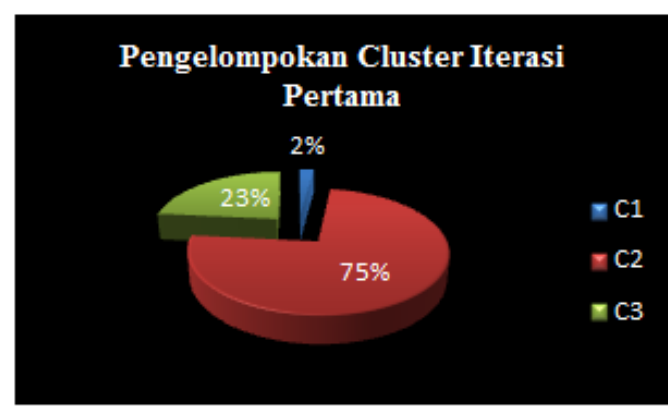

Gambar 5. Pengelompokan Cluster Pertama

Terus dilakukan perhitungan hingga data objek tidak berubah tempat. Pada penelitian ini data yang dihitung berhenti pada iterasi ke enam. (J. O. Ong, 2013)

\section{HASIL DAN PEMBAHASAN}

\section{A. Hasil Penelitian}

Hasil penelitian berisi pengelompokan data ke dalam tiap-tiap klaster yang dibutuhkan. hasil pengelompokan data daerah pungutan liar yang telah dihitung menggunakan metode K-Means. Implementasi di dalam sistem pengelompokan data kecamatan tentang pungutan liar didapat dari analisa dan desain sistem pada BAB sebelumnya. Data hasil penelitian dimasukkan secara komputerisasi dalam bentuk pengelompokan daerah pungutan liar yang dibangun menggunakan bahasa pemrograman PHP dan MySQL sebagai database, kemudian hasil perhitungan dan eksekusi sistem dari metode KMeans.

\section{B. Hasil Klasifikasi Pungutan Liar}

Dari 479 data yang akan dihitung menggunakan metode K-Means. Diketahui bahwa terdapat 13 kecamatan yang masuk kedalam cluster tingkat pungutan liar tinggi (C1) yaitu Cireunghas, Geger Bitung, Kalapa Nunggal, Kalibunder, Purabaya, Simpenan, Parung Kuda, Sukaraja, Nagrak, Nyalindung, Pelabuhanratu, Surade, dan Warungkiara, 19 tingkat pungutan liar sedang (C2) yaitu Bojong Genteng, Sukalarang, Waluran, Bantargadung, Curugkembar, Ciambar, Gunungguruh, Pabuaran, Cimanggu, Cidahu, Ciracap, Cibadak, Kecamatan, Cikembar, Jampang Kulon, Jampang Tengah, Cikidang, Sagaranten, Cicurug, dan Cisolok, dan 16 kecamatan tingkat pungutan liar rendah (C3) yaitu Cidolog, Kebonpedes, Kecamatan, Lengkong, Cibitung, Cidadap, Kabandungan, Parakan Salak, Sukabumi, Cicantayan, Tegalbuleud, Caringin, Ciemas, Cikakak, Kadudampit, dan Cisaat pada hasil perhitungan laporan pada bulan januari 2019.

\section{Implementasi Sistem}

\section{Halaman Utama}

Halaman Utama merupakan tampilan pertama yang ditampilkan khusus untuk pelapor (warga 
masyarakat kabupaten Sukabumi) untuk melaporkan kejadian pungutan liar yang pelapor alami.

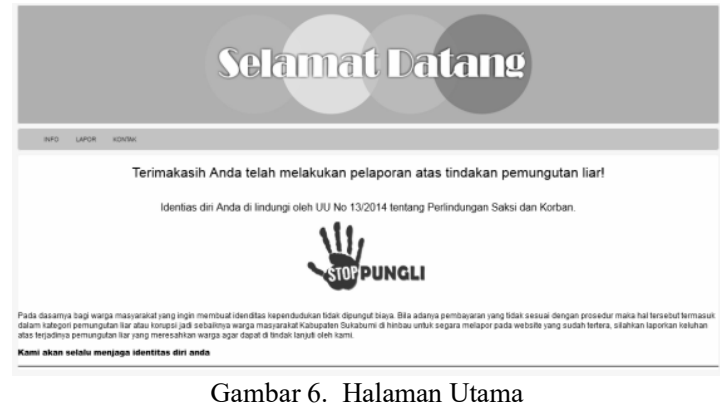

\section{Halaman Lapor}

Pelapor atau warga kabupaten Sukabumi dapat melaporkan kejadian pungutan liar dengan mengisi data yang telah tertera di form yang telah ditentukan oleh pihak dinas. Data diri pelapor tidak akan dipublikasikan atau disebar luaskan karena data pelapor dilindungi oleh perundang-undangan 1945. Berikut tampilan Halaman Lapor:

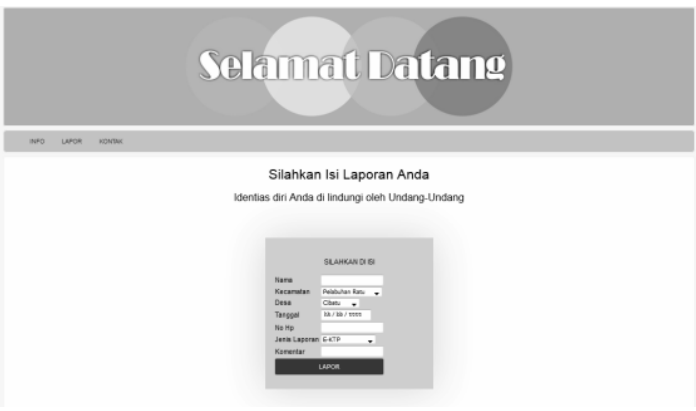

Gambar 7. Halaman Lapor

\section{Halaman Login Admin}

Halaman Login merupakan halaman khusus untuk admin agar dapat mengakses data laporan warga yang sudah terinput ke dalam sistem. Akses admin yang diberikan tergantung kesepakatan pihak dinas siapa saja yang dapat mengakses menu halaman login admin oleh sebab itu peneliti tidak memberikan registrasi agar tidak terjadi user yang bukan pegawai dinas. Berikut tampilan login halaman admin:

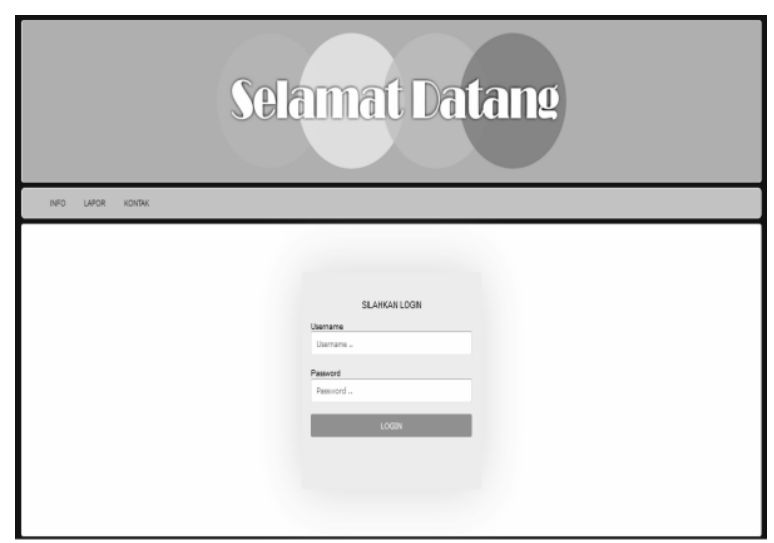

Gambar 8. Halaman Login Admin

\section{Halaman Admin}

Setelah admin melakukan login maka halaman selanjutnya yang ditampilkan adalah halaman admin untuk proses penghitungan data dan melihat jumlah data laporan yang sudah masuk ke dalam sistem. Berikut tampilan halaman admin:

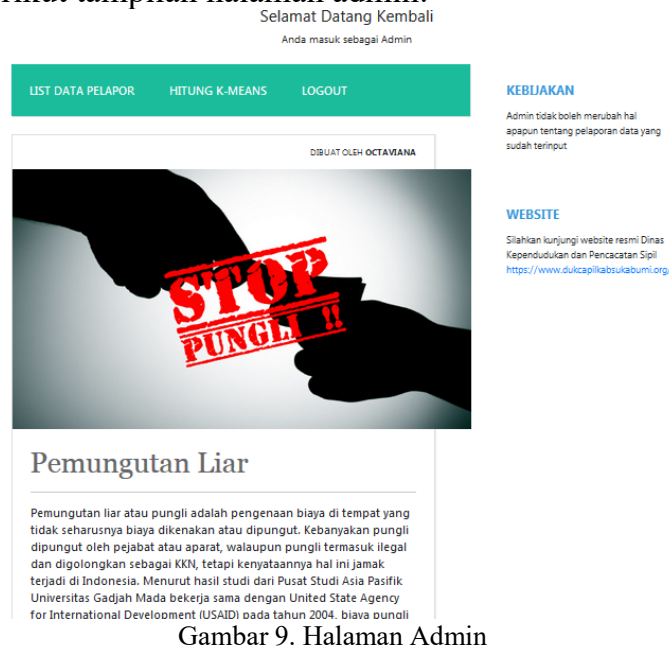

\section{List Data Pelapor}

Halaman ini hanya bisa diakses oleh admin dan admin bersangkutan tidak dapat merubah atau menghapus data dari hasil laporan warga kabupaten Sukabumi atas keluhan pungutan liar yang terjadi atau maraknya calo di kecamatan tersebut, karena apabila di halaman ini admin diberikan akses hapus dan edit maka bisa terjadinya pemalsuan atau pelenyapan data. Oleh sebab itu admin hanya dapat melihat sudah berapa banyak laporan yang sudah terinput. Berikut tampilan halaman list data laporan warga kabupaten Sukabumi :

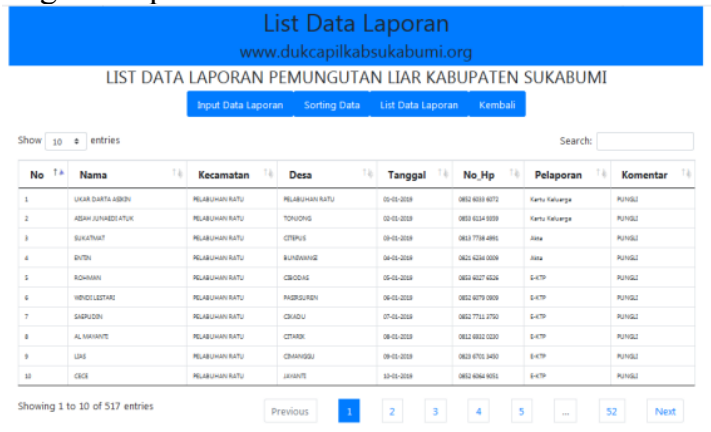

Gambar 10. Halaman List Data Laporan

\section{Sorting Data}

Setelah data laporan warga kabupaten Sukabumi didapat maka data akan di sorting sesuai dengan kebutuhan yang ingin dieksekusi selanjutnya. Berikut tampilan halaman sorting data : 

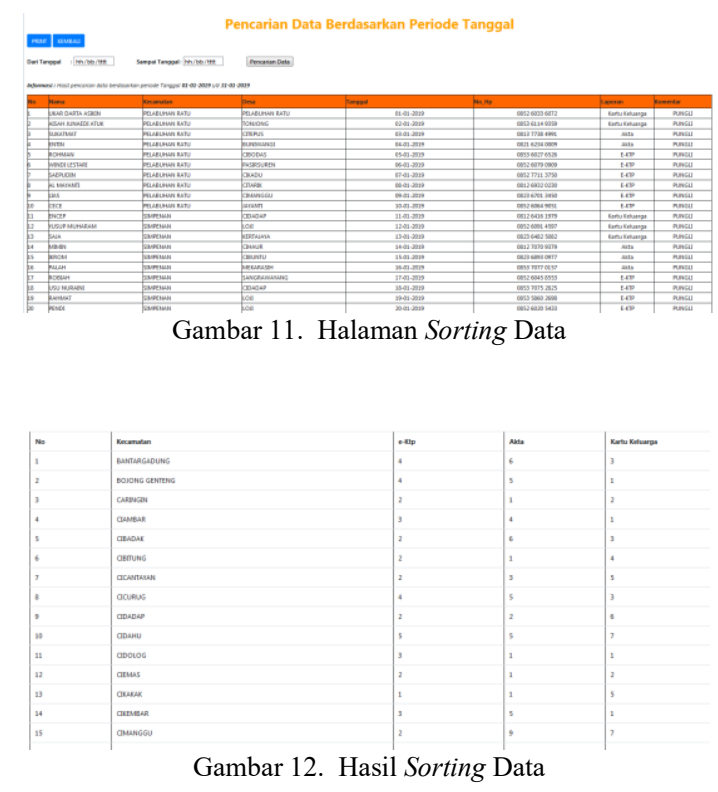

\section{Nilai Bobot}

Apabila data telah ter-sorting maka yang selanjutnya dilakukan oleh admin ialah memasukkan nilai bobot untuk setiap variabel yang memiliki nilai bobot yang berbeda sesuai dengan kesepakatan peneliti dan dinas. Berikut tampilan penginputan nilai bobot:

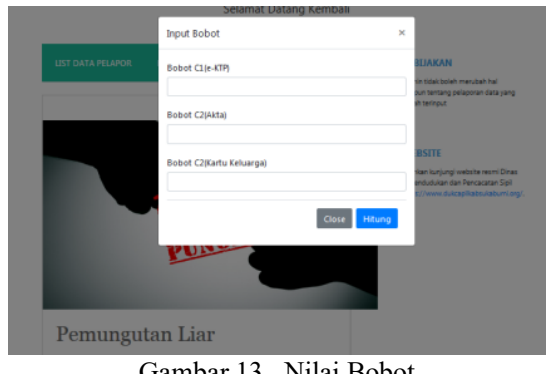

\section{Hitung K-Means}

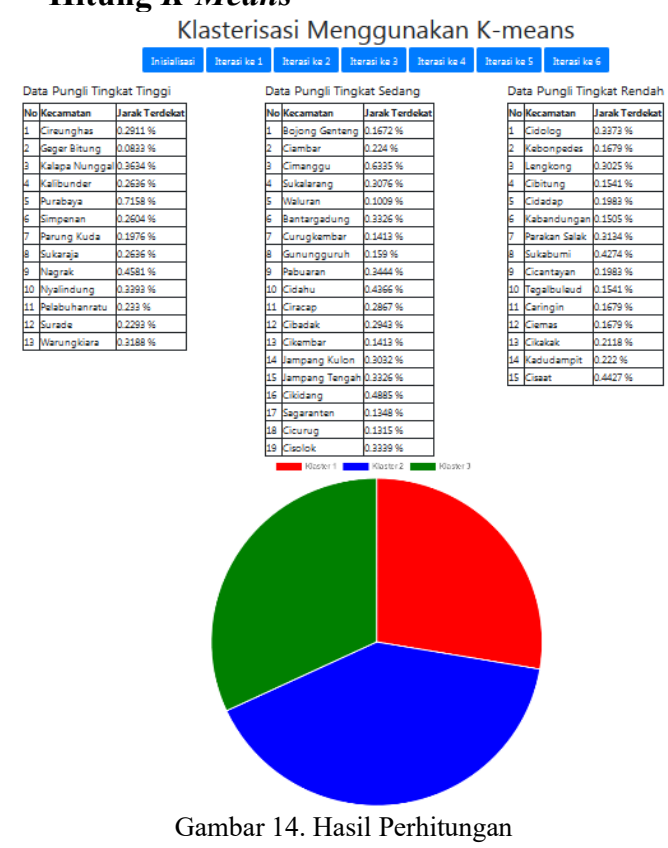

Bila nilai bobot sudah dimasukkan maka selanjutnya halaman akan menampilkan hasil perhitungan menggunakan metode $k$-means dengan data yang sudah tersorting sebelumnya. halaman perhitungan menggunakan metode $k$-means clustering untuk penentuan kecamatan mana saja yang masuk ke dalam tiga cluster pungutan liar tinggi, sedang, dan rendah ditunjukan pada Gambar 14.

\section{Pembahasan}

Data yang digunakan dalam penelitian ini yaitu hasil laporan warga kabupaten Sukabumi yang masih terjadinya pungutan liar terhadap warga oleh orang tertentu atau melalui calo untuk mengurus pencatatan sipil. Penulis menggunakan metode kmeans untuk pengelompokan daerah pungutan liar ke dalam tiga golongan.

Dalam penelitian ini, proses analisis yang dilakukan untuk mengelompokkan pungutan liar di setiap kecamatan yang ada di kabupaten Sukabumi untuk periode 1 bulan dan dibantu dengan pihak dinas kependudukan dan pencatatan sipil serta melakukan wawancara. Sistem yang digunakan dalam perhitungan metode k-means clustering yaitu php mysql dengan pengkodingan menggunakan sublime untuk pengimplementasian sistem dengan menerapkan metode yang peneliti gunakan.

Hasil perhitungan dari sistem tidak jauh berbeda dengan perhitungan manual yaitu sebanyak 13 kecamatan masih marak terjadinya pungutan liar melalui calo setempat di kecamatan tersebut atau para pegawai dinas yang meminta bayaran secara tersirat dan 19 kecamatan masuk ke dalam kelompok tingkat pungutan liar sedang, sementara 15 kecamatan masuk kedalam pungutan liar rendah. Setelah sistem telah selesai dibuat warga dapat melapor tanpa harus melakukan login warga langsung melakukan pelaporan pada sistem dan hasil laporan tersebut akan simpan pada database, tahapan selanjutnya akan dilakukan proses pengelompokan menggunakan metode k-means clustering oleh admin dinas kependudukan dan pencatatan sipil.

Sistem akan menampilkan grafik pengelompokan data dengan hasil yang sesuai dengan data hasil laporan warga kabupaten Sukabumi terhadap terjadinya pungutan liar. Hasil dari pengelompokan daerah pungutan liar ini dapat digunakan sebagai data evaluasi untuk program kerja penyuluhan terhadap warga kabupaten Sukabumi oleh dinas kependudukan dan pencatatan sipil.

\section{KESIMPULAN DAN SARAN}

Metode K-Means dapat diimplementasikan ke dalam sistem dengan menggunakan PHP dan MySQL untuk membantu pengelompokan hasil laporan 
warga terhadap pungutan liar di setiap kecamatan kabupaten Sukabumi.

Hasil penelitian ini memperoleh data indeks kecamatan dengan tingkat jumlah laporan masyarakat daerah terhadap pungutan liar, data dengan kasifikasi tingkat tinggi yaitu Cireunghas, Gegerbitung, Kalapa Nunggal, Kalibunder, Purabaya, Simpenan, Parung Kuda, Sukaraja, Nagrak, Nyalindung, Pelabuhanratu, Surade, Warungkiara. Data tingkat pungutan liar sedang terdapat pada 19 kecamatan dan 15 tingkat pungutan liar rendah. Sebagai saran juga kepada dinas kependudukan dan pencatatan sipil, kecamatan yang menjadi tindakan pungutan liar paling tinggi diprioritaskan untuk melakukan penyuluhan kepada kecamatan tersebut.

\section{DAFTAR PUSTAKA}

Calo dan Pungli Masih Marak, Ombudsman RI: Masyarakat Tak Mau Repot dan Pilih Jalan Pintas - Ombudsman RI. (n.d.). Retrieved February 4, 2020, from https://ombudsman.go.id/perwakilan/news/r/p wk--calo-dan-pungli-masih-marakombudsman-ri-masyarakat-tak-mau-repot-danpilih-jalan-pintas

Ghosh, S., \& Kumar, S. (2013). Comparative Analysis of K-Means and Fuzzy C-Means Algorithms. International Journal of Advanced Computer Science and Applications, 4(4). https://doi.org/10.14569/ijacsa.2013.040406

Gustian, D., Yulitasari, S., Hundayani, D., Muslih, \& Nunik. (2018). Comparison of C4.5 method based optimization algorithm to determine eligibility of beneficiaries of direct community assistance (Case study: Kelurahan Cicurug). 3rd International Conference on Computing, Engineering, and Design, ICCED 2017. https://doi.org/10.1109/CED.2017.8308109

Kumala, A. R., \& Wutsqa, D. U. (2016). Perbandingan K-Means Dan Fuzzy C-Means Clusteringpada Model Radial Basis Function Neural Network(Rbfnn) Untuk Klasifikasi Stadium Kanker Payudara.

Pratama, A. Y., Prabowo, I. A., \& Normassari, A. (2017). (Alpukat) Aplikasi Pengaduan Masyarakat Untuk Melaporkan Kejadian Pungutan Liar Di Kabupaten Kudus Berbasis Android. Simetris: Jurnal Teknik Mesin, Elektro Dan Ilmu Komputer, 8(2), 399. https://doi.org/10.24176/simet.v8i2.1119

Rante Rerung, R. (2018). Penerapan Data Mining dengan Memanfaatkan Metode Association Rule untuk Promosi Produk. Direvisi: $27 \mathrm{Mei}$, 3(1). https://doi.org/10.31544/jtera.v3.i1.2018.89-98

Seberapa Pentingkah NIK, Data Kependudukan dan KTP Elektronik? (n.d.). Retrieved February 4,
2020, from

http://dukcapil.bangka.go.id/berita/detail/seber apa-pentingkah-nik-data-kependudukan-danktp-elektronik

Sembiring, F., \& Sari, D. P. (2019). Design Process Data Storage and Organize Data Scraping. 1(1), 22-26.

Windarto, A. P. (2017). Penerapan Datamining Pada Ekspor Buah-Buahan Menurut Negara Tujuan Menggunakan K-Means Clustering Method. Techno.Com, 16(4), 348-357. https://doi.org/10.33633/tc.v16i4.1447 